\title{
Neurological aspects of HTLV-1 infection in Bahia: results from an 8-year cohort
}

Aspectos neurológicos da infecção pelo HTLV-1 na Bahia: resultados de uma coorte de 8 anos

Davi Tanajura

Resumo da Tese de Doutorado apresentada ao Programa de Pós-graduação em Ciências da Saúde da Universidade Federal da Bahia. Salvador BA, Brasil, 2013.

Correspondence: Davi Tanajura; Rua Sócrates Guanaes Gomes, 107 / ap. 402; 40286-720 Salvador BA, Brasil; E-mail: davicostamd@gmail.com

Orientador: Edgar M. de Carvalho.

Received 25 April 2014; Received in final form 18 September 2014; Accepted 8 September 2014.

\section{ABSTRACT}

HTLV-1 is the causal agent of HTLV-1-associated myelopathy/tropical spastic paraparesis (HAM/TSP), a disease observed in up to $5 \%$ of individuals infected with HTLV-1. However, infected individuals without the disease can present neurological complaints relating to sensory, motor or urinary manifestations. The aim of this study was to investigate the incidence of neurological manifestations among patients with HTLV-1. Method: HTLV-1 patients in Salvador, Bahia, Brazil, were enrolled into a cohort study. Results: Among 414 subjects, 76 had definite and 87 had possible or probable HAM/TSP at the baseline, whereas 251 subjects had no neurological signs or symptoms. Definite HAM/TSP developed in 5 patients (1.74\%). The asymptomatic subjects were selected for analysis. The incidence rate expressed per 1,000 persons-year was calculated. It was 206 for hand numbness, 129 for nocturia and 126 for urinary urgency. In the neurological examination, leg hyperreflexia presented an average incidence rate of 76; leg paraparesis, 52; and Babinski sign, 36. Kaplan-Meyer curves categorized according to gender and proviral load showed that females and patients with proviral load of more than 100,000 copies per 106 peripheral blood mononuclear cells (PBMCs) presented higher risk. Conclusion: Development of neurological symptoms or signs occurred in up to $30 \%$ of asymptomatic subjects during 8 years of follow-up. Female gender and high proviral load were risk factors for neurological disease.

Keywords: HTLV-1, HAM/TSP, cohort. 